\section{Response to ACMG guideline: Carrier screening in individuals of Ashkenazi Jewish decent}

\section{To the Editor:}

Establishing American College of Medical Genetics (ACMG) guidelines for carrier testing in individuals of Ashekanzi Jewish descent $^{1}$ is both timely and necessary, and we commend the authors and the ACMG for their effort in this regard. The authors comment that "there is no specific panel of tests available for Jews from non-Ashkenazi background," but there are founder mutations in specific non-Ashkenazi groups (e.g., for Phenylketonuria and Metachromatic Leukodystrophy in Yemenite Jews, for Fanconi anemia A and Ataxia Telangiectasia in North African Jews). These tests are appropriate for couples who share specific nonAshkenazi ethnicity, and are readily available in Israel.

Beyond a list of specific diseases, the guidelines appropriately include criteria for evaluating further genetic tests, as they become available. However, the list itself is inconsistent with these criteria, in part because existence of treatment is not noted as a consideration, and in part because the recommendations mirror, rather than challenge, current practice. Gaucher disease is included in the list of diseases recommended for screening even though the disease associated with the most common mutation, N370S, does not meet the author's own criterion 2a.: "The natural history of the disorder should be well understood and carry a potential for significant morbidity and/or mortality in the homozygous or compound heterozygous state." The natural history of N370S homozygotes/compound heterozygotes unpredictably ranges from "bad to normal"2 and even "bad" cases are treatable with enzyme replacement therapy. Most carrier screening is not performed premaritally but in couples planning pregnancies, leading to subsequent prenatal testing and possible termination of affected pregnancies. In our recent study on the outcome of postmarital Gaucher disease carrier screening in Israel, prenatal diagnosis was used in $76 \%$ of pregnancies in carrier couples identified, leading to pregnancy termination in $31 \%$ of fetuses diagnosed with Gaucher disease (15\% in N370S homozy- gotes and $66 \%$ in N370S compound heterozygotes). ${ }^{3}$ Gaucher disease in these cases would have ranged from asymptomatic to treatable. Although it could be argued that couples deserve to be informed of all available tests and reach their own, autonomous decision, as a profession, we cannot ignore that screening for low penetrance, treatable disease will lead to questionable pregnancy terminations. Professional associations including the National Institutes of Health Technology Assessment Panel on Gaucher Disease $^{4}$ the Israeli Medical Association, ${ }^{5}$ and the Canadian Society of Obstetrics and Gynecology and College of Medical Geneticists $^{6}$ have recommended against carrier screening for Gaucher disease. We are acutely aware that Gaucher disease carrier screening continues to be offered, in response to both economic and altruistic pressures. $^{2}$ However, the genotype/phenotype correlation in Gaucher disease remains poor, and to the best of our knowledge, the ACMG is the first professional body to recommend Gaucher carrier screening. The genetics community has resisted carrier screening for deafness in Ashkenazi Jews, even though the carrier frequency of two founder mutations (30delG and $167 \mathrm{delT}$ ) is $4.76 \%,{ }^{7}$ and they account for $>90 \%$ of disease alleles. This reflects sensitivity to the question of defining deafness as a morbidity justifying pregnancy termination, especially because effective treatment exists. Along these lines, we urge the ACMG guidelines committee to reconsider their recommendation for Gaucher disease carrier screening.

$$
\begin{array}{r}
\text { Ephrat Levy-Lahad, MD } \\
\text { Shachar Zuckerman, MSc } \\
\text { Medical Genetics Unit } \\
\text { Shaare Zedek Medical Center } \\
\text { Jerusalem, Israel } \\
\text { Hebrew University-Hadassah Medical School } \\
\text { Jerusalem, Israel } \\
\text { Michal Sagi, PhD } \\
\text { Hadassah Hospital } \\
\text { Jerusalem, Israel } \\
\text { Department of Human Genetics } \\
\text { Jerusalem, Israel }
\end{array}
$$

\section{References}

1. Gross SJ, Pletcher BA, Monaghan KG. Carrier screening in individuals of Ashkenazi Jewish descent. Genet Med 2008;10:54-56.

2. Beutler E. Carrier screening for Gaucher disease: more harm than good? JAMA 2007, 298:1329-1331.

3. Zuckerman S, Lahad A, Shmueli A, Zimran A, et al. Carrier screening for Gaucher disease: lessons for low-penetrance, treatable diseases. JAMA 2007;298:1281-1290.

4. Gaucher disease. Current issues in diagnosis and treatment. NIH Technology Assessment Panel on Gaucher Disease. JAMA 1996;275:548-553.

5. Position paper: carrier screening for Gaucher disease. Chapter in position papers: topic: carrier screening for genetic disease. Israel Medical Association, 2004.

6. Langlois S, Wilson RD. Genetics Committee of the Society of Obstetricians and Gynaecologists of Canada (SOGC); Prenatal Diagnosis Committee of the Canadian College of Medical Geneticists (CCMG). Carrier screening for genetic disorders in individuals of Ashkenazi Jewish descent. J Obstet Gynaecol Can 2006;28:324-343.

7. Morell RJ, Kim HJ, Hood LJ, Goforth L, et al. Mutations in the connexin 26 gene (GJB2) among Ashkenazi Jews with nonsyndromic recessive deafness. N Engl J Med 1998;339:1500-1505. 